\title{
Evaluation of adhesion forces of Staphylococcus aureus along the length of Candida albicans hyphae
}

\author{
Ekaterina S Ovchinnikova ${ }^{1}$, Bastiaan P Krom ${ }^{1,2}$, Henk J Busscher ${ }^{1}$ and Henny C van der Mei ${ }^{\text {1* }^{*}}$
}

\begin{abstract}
Background: Candida albicans is a human fungal pathogen, able to cause both superficial and serious, systemic diseases and is able to switch from yeast cells to long, tube-like hyphae, depending on the prevailing environmental conditions. Both morphological forms of $C$. albicans are found in infected tissue, often in combination with Staphylococcus aureus. Although bacterial adhesion to the different morphologies of $C$. albicans has been amply studied, possible differences in staphylococcal adhesion forces along the length of $C$. albicans hyphae have never been determined. In this study, we aim to verify the hypothesis that the forces mediating $S$. aureus NCTC8325-4 GFP adhesion to hyphae vary along the length of C. albicans SC5314 and MB1 hyphae, as compared with adhesion to yeast cells.

Results: C. albicans hyphae were virtually divided into a "tip" (the growing and therefore youngest part of the hyphae), a "middle" and a so-called "head" region (the yeast cell from which germination started). Adhesion forces between S. aureus NCTC8325-4 ${ }^{\text {GFP }}$ and the different regions of C. albicans SC5314 hyphae were measured using atomic force microscopy. Strong adhesion forces were found at the tip and middle regions of $C$. albicans hyphae $(-4.1 \mathrm{nN}$ and $-4.0 \mathrm{nN}$, respectively), while much smaller adhesion forces were measured at the head region $(-0.3$ $\mathrm{nN}$ ). Adhesion forces exerted by the head region were comparable with the forces arising from budding yeast cells $(-0.5 \mathrm{nN})$. A similar regional dependence of the staphylococcal adhesion forces was found for the clinical isolate involved in this study, C. albicans MB1.

Conclusions: This is the first time that differences in adhesion forces between $S$. aureus and different regions of $C$. albicans hyphae have been demonstrated on a quantitative basis, supporting the view that the head region is different from the remainder of the hyphae. Notably it can be concluded that the properties of the hyphal head region are similar to those of budding yeast cells. These novel findings provide new insights in the intricate interkingdom interaction between C. albicans and S. aureus.
\end{abstract}

Keywords: Bacteria, Yeast, Interaction, Adhesion forces, AFM

\section{Background}

Candida albicans is an opportunistic human pathogen and the leading cause of a wide range of human fungal infections. C. albicans is a polymorphic fungus and either grows as a unicellular budding yeast cell or in a filamentous, (pseudo)hyphal form, depending on environmental conditions, such as temperature, $\mathrm{pH}$ or

\footnotetext{
* Correspondence: h.c.van.der.mei@umcg.nl

'Department of Biomedical Engineering, University of Groningen and University Medical Center Groningen, Antonius Deusinglaan 1, Groningen, AV 9713, The Netherlands

Full list of author information is available at the end of the article
}

presence of chemical stimuli such as serum components or N-acetylglucosamine [1-3]. The ability to switch between different morphologies is important for C. albicans virulence $[4,5]$. It is presumed that yeast cells facilitate dissemination to target organs, whereas hyphae play a role in further tissue invasion due to the ability to adhere to and pierce host epithelial and endothelial cells, damaging them through the release of hydrolytic enzymes and initiate candidiasis [5-7]. C. albicans morphological plasticity also plays an important role in biofilm formation and maturation. C. albicans mutants unable to perform morphological switches can develop

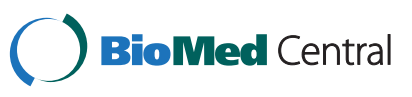


only rudimentary biofilms, that are structurally less stable than wild type biofilms [8-10].

C. albicans co-exists with a highly diverse bacterial flora in various sites of the human body, resulting in mixed species biofilms [11,12]. For survival and reproductive success, interacting microorganisms in polymicrobial communities are involved in antagonistic or synergistic relationships. C. albicans is often co-isolated with Pseudomonas aeruginosa during catheter-associated infections or infections of patients suffering from cystic fibrosis and burn wounds [13-16]. P. aeruginosa can specifically adhere to $C$. albicans hyphae but not to yeast cells, which leads to rapid lysis and death of hyphae through a currently unidentified mechanism $[17,18]$. $C$. albicans and Streptococcus gordonii on the other hand, form a synergistic partnership since these streptococci enhance $C$. albicans filamentation, whereas C. albicans can stimulate streptococcal biofilm formation on different kind of surfaces [19].

Klotz et al. [20] showed that in approximately $11 \%$ of polymicrobial bloodstream infections, C. albicans was co- isolated in conjunction with Staphylococcus aureus. Moreover, C. albicans and S. aureus are able to form complex polymicrobial biofilms on various mucosal surfaces, and within a biofilm $S$. aureus is mostly associated with hyphal cells and not with yeast cells [21,22]. Interestingly, co-infection of mice with $C$. albicans and $S$. aureus demonstrated a synergistic effect, resulting in increased mice mortality [23,24]. Furthermore, recent in vitro and in vivo studies demonstrated that $S$. aureus may use adhesion to C. albicans hyphae to become invasive. Using an ex vivo murine tongue model, it was shown that oral cocolonization by $C$. albicans and S. aureus led to penetration of tongue tissue by hyphae with adhering S. aureus [25].

Atomic Force Microscopy (AFM) is a state-of-the-art technique that allows recording of the actual adhesion force that occurs between a bacterium and C. albicans (see Figure 1A). AFM has recently been applied to identify the nature of the adhesion forces between $P$. aeruginosa and C. albicans [26]. Bacterial adhesion to hyphae was always accompanied by strong adhesion forces, but did not occur to yeast cells. Poisson analyses of adhesion

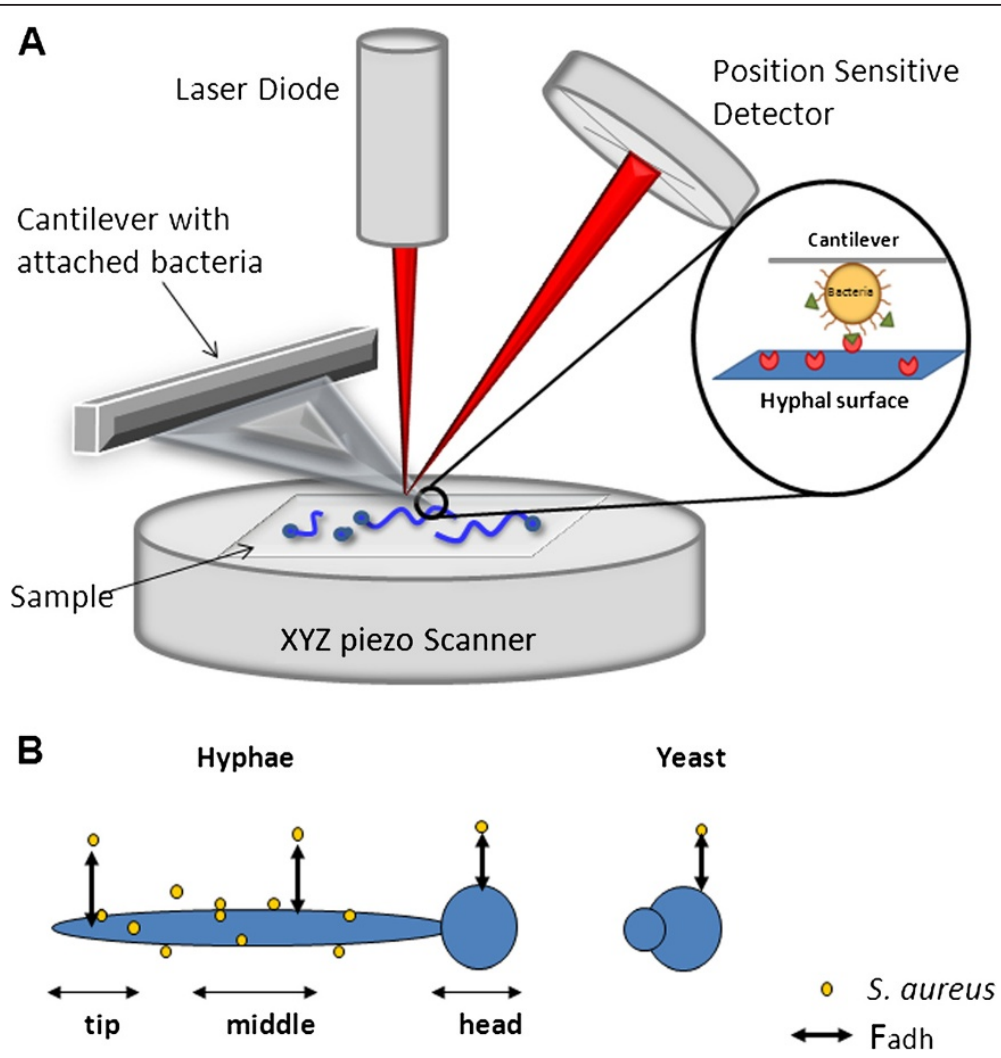

Figure 1 Schematic illustration of the principle of atomic force microscopy and definition of different hyphal regions. (A) Schematic presentation of AFM set-up. A sample with attached C. albicans cells is positioned by a xyz piezo scanner, while a bacterium attached to a tipless AFM cantilever is brought into contact with the hyphal surface. The deflection of the cantilever upon retract is a measure of the adhesion forces between a bacterium and the hyphal surface and is detected by an optical laser. The laser beam is focused on the very end of the cantilever and reflected onto a position sensitive detector from which the adhesion forces can be calculated, provided the mechanical properties of the cantilever are known. (B) Schematic indication of the different hyphal regions defined for bacterial-hyphal adhesion force measurements. 
forces indicated that the outermost mannoprotein-layer on hyphal surfaces created favorable acid-base conditions for adhesion, allowing close approach of $P$. aeruginosa. Removal of these proteins caused unfavorable acid-base conditions, preventing adhesion of $P$. aeruginosa. Despite the notable importance of $C$. albicans morphological plasticity for bacterial-fungal interaction, possible differences in bacterial adhesion forces along the length of $C$. albicans hyphae have never been determined. Hyphae grow in a linear mode, with the tip of the hyphae representing the youngest part and the region closer to the original germinating yeast cell being the oldest. Here we hypothesize, that these differences along the length of a hypha may impact the adhesion forces with bacteria. The aim of this paper is to verify this hypothesis. To this end, we virtually divided (see Figure 1B) C. albicans hyphae into a "tip" (the growing end of the hyphae), a "middle" and a so-called head region (the yeast cell from which germination started) and measured actual adhesion forces that occur between these hyphal regions of two different $C$. albicans strains and a $S$. aureus strain using AFM.

\section{Methods}

\section{Strains, growth conditions and harvesting}

C. albicans SC5314 (a commonly used, wild type reference strain), C. albicans MB1 (a biofilm-associated, clinical isolate [27]) and bacterial strain S. aureus NCTC8325-4 (wild type) were used. To generate green fluorescent protein (GFP)-expressing $S$. aureus NCTC8325-4, pMV158GFP [28] was introduced into competent bacterial cells by electroporation [29]. Selection of subsequent transformants was performed on tryptone soya broth with $1.5 \%$ bactoagar (TSB, Oxoid, Basingstoke, UK) plates containing $10 \mu \mathrm{g} / \mathrm{mL}$ tetracycline. S. aureus NCTC8325-4 that received pMV158GFP (S. aureus NCTC8325-4 ${ }^{\mathrm{GFP}}$ ) showed constitutive GFP expression that could be visualized using fluorescence microscopy.

Strains were grown on TSB agar plates, supplemented with tetracycline when appropriate. Single colonies were inoculated in $5 \mathrm{~mL}$ TSB containing $10 \mu \mathrm{g} / \mathrm{mL}$ tetracycline for bacterial pre-cultures or $5 \mathrm{~mL}$ yeast nitrogen base acids (YNB; Difco, Sparks, USA) pH 7, containing $0.5 \%$ D-glucose for C. albicans pre-cultures. S. aureus was routinely grown at $37^{\circ} \mathrm{C}$ while $C$. albicans was grown at $30^{\circ} \mathrm{C}$ to prevent hyphal formation for $24 \mathrm{~h}$ with rotation $(150 \mathrm{rpm})$ and used to inoculate a main culture (1:50 dilution of pre-culture). Main bacterial cultures were grown for an additional $18 \mathrm{~h}$ under the same conditions. C. albicans hyphae were induced by growing a culture (1:50 dilution) for $4 \mathrm{~h}$ with rotation $(150 \mathrm{rpm})$ at $37^{\circ} \mathrm{C}$ in 12 wells tissue culture polystyrene plates (Costar, Corning Inc., NY, USA). Hyphal formation was obtained at $90-95 \%$ efficiency under these conditions, as confirmed by phase contrast microscopy. Main cultures were harvested by centrifugation for $5 \mathrm{~min}$ at $6,250 \times \mathrm{g}$ and $14,800 \times g$ for $S$. aureus and C. albicans, respectively, followed by two washes with phosphate buffered saline (PBS: $10 \mathrm{mM}$ potassium phosphate, $0.15 \mathrm{M}$ sodium chloride, $\mathrm{pH}$ 7) and resuspended in PBS.

\section{Adhesion of staphylococci to hyphae and yeast using fluorescence microscopy}

Adhesion of S. aureus NCTC8325-4 ${ }^{\mathrm{GFP}}$ to C. albicans in its hyphal morphology was verified using fluorescence microscopy (Leica DM4000B, Heidelberg, Germany). After $4 \mathrm{~h}$ of hyphal formation, wells were washed once with PBS. Bacteria were added to a final optical density measured at $600 \mathrm{~nm}\left(\mathrm{OD}_{600}\right)$ of 0.1 in PBS. After $3.5 \mathrm{~h}$ of co-incubation with staphylococci at $37^{\circ} \mathrm{C}$ under static conditions, wells were gently washed two times with PBS and C. albicans hyphae were counter-stained with Calcofluor White $(35 \mu \mathrm{g} / \mathrm{mL}, 15 \mathrm{~min}$ at room temperature), known to bind to chitin-rich areas of the fungal cell wall. Note that PBS was used in order to avoid the influence of growth, while co-incubation was done at $37^{\circ} \mathrm{C}$ in order to mimic the human body temperature. Afterwards, images were taken at five randomly chosen locations in the wells using a $40 \mathrm{x}$ water immersion objective using filter sets for GFP and UV. All experiments were performed in triplicate with separately grown cultures.

\section{Staphylococcal adhesion forces along hyphae using atomic force microscopy}

Adhesion forces between S. aureus NCTC8325-4 ${ }^{\mathrm{GFP}}$ and hyphae were measured at room temperature in PBS using an optical lever microscope (Nanoscope IV, Digital Instruments, Woodbury, NY, USA) as described before [26]. Briefly, C. albicans was immobilized on glass slides (Menzel, GmbH, Germany), coated with positively charged poly-L-lysine. A fungal suspension was deposited onto the coated glass and left to settle at room temperature for $20 \mathrm{~min}$. Non-adhering cells were removed by rinsing with demineralized water and the slide was kept hydrated prior to AFM analysis in phosphate buffer. To create a bacterial probe, $S$. aureus was immobilized onto poly-L-lysine treated tipless "V"shaped cantilevers (DNP-0, Veeco Instruments Inc., Woodbury, NY, USA). Bacterial probes were freshly prepared for each experiment.

AFM experiments were performed at room temperature due to the limitations of the equipment. This is unlikely to have an effect on the outcome of physico-chemical measurements such as of adhesion forces, as here the absolute temperature scale, that is in Kelvin units, is relevant. On a Kelvin scale the change 
from $37^{\circ} \mathrm{C}$ to $22^{\circ} \mathrm{C}$ is very small, decreasing only from 293 Kelvin to 273 Kelvin.

For each bacterial probe, force curves were measured after different bond-maturation times up to $60 \mathrm{~s}$ on the same, randomly chosen spot on a hyphal or yeast cell with a z-scan rate of less than $1 \mathrm{~Hz}$. To ensure that no bacteria detached from the cantilever during the experiment, control force-distance curves were made with $0 \mathrm{~s}$ contact time after each set of measurements. Whenever the " $0 \mathrm{~s}$ contact time" forces measured deviated more than $0.5 \mathrm{nN}$ from the initial measurement, a bacterial probe was considered damaged and replaced. For each combination of a bacterial strain and fungal-coated glass surface, five different probes were employed on average and the number of bacterial probes used depended on the outcome of the control measurements. Calibration of each cantilever was done using the thermal tuning method (Nanoscope V6.13r1), yielding a range of spring constants from 0.03 to $0.06(\mathrm{~N} / \mathrm{m})$.

\section{Statistics}

Typically, measured bacterial adhesion forces contained a large spread and were not normally distributed (Shapiro-Wilk test, $\mathrm{P}<0.01$ ). Hence, data are presented as median and interquartile range. Adhesion forces for different fungus-bacterium pairs were compared using non-parametric analyses (Mann-Whitney test). Differences were considered significant when the P-value was $<0.05$.

\section{Results}

Adhesion of staphylococci to hyphae and yeast cells using fluorescence microscopy

In order to assess the adhesion of S. aureus NCTC8325$4^{\mathrm{GFP}}$ along the length of $C$. albicans hyphae, we used two different fungal strains: C. albicans SC5314 and C. albicans MB1. Bacterial adhesion to hyphae was visualized with fluorescent microscopy and quantitated by enumeration of adhering bacteria per unit hyphal length (Figure 2). Most bacteria adhered to the tip and middle regions of the hyphae and adhered only scarcely to the head region of the hyphae or to non-germinating yeast cells (Figure 2C). Note that strictly speaking, a comparison of the number of staphylococci adhering per unit hyphal length may not be directly compared with the number of bacteria adhering to a non-germinating yeast cell. Both $C$. albicans strains showed the same trend, although bacteria adhered to C. albicans SC5314 in higher numbers than to the clinical isolate MB1.

\section{Adhesion force along the hyphae using atomic force microscopy}

Adhesion forces between S. aureus NCTC8325-4 ${ }^{\mathrm{GFP}}$ and both $C$. albicans strains along the hyphae were determined using AFM (Figure 1). Figure 3 shows typical examples of force-distance curves of the $S$. aureus probe upon approach and retract from C. albicans hyphae and yeast surfaces at initial contact and after $60 \mathrm{~s}$ surface delay. Major differences existed in AFM force-distance curves recorded immediately upon contact $(0 \mathrm{~s})$ and after a 60 s surface delay between $S$. aureus NCTC8325$4^{\mathrm{GFP}}$ and different hyphal regions and the yeast cell, as summarized in Figure 4. In line with the higher number of bacteria adhering to the tip and middle regions of $C$. albicans hyphae (Figure 2C), stronger adhesion forces (around $4 \mathrm{nN}$ for SC5314 and around $2 \mathrm{nN}$ for MB1) were recorded after bond-maturation between these regions than for the head regions (around $0.5 \mathrm{nN}$ ). However, adhesion forces measured between $S$. aureus NCTC8325-4 ${ }^{\mathrm{GFP}}$ and both yeast cells remained comparable to the adhesion forces measured to the head region of the hyphae, irrespective of bond-maturation (Figures $4 \mathrm{~A}$ and $4 \mathrm{~B}$ ). Note that in general, adhesion forces, especially after bond-maturation, were significantly smaller between $S$. aureus and the hyphal regions of C. albicans SC5314 than between S. aureus and C. albicans MB1 hyphal middle and tip regions (compare Figures $4 \mathrm{~A}$ and $4 \mathrm{~B})$.

\section{Discussion}

In this study, we hypothesized that $S$. aureus adhesion may vary along the length of $C$. albicans hyphae. To this end, our study was designed to determine the actual physical interaction between $S$. aureus and hyphae, contingently divided into three regions, i.e. a head, middle and tip region. S. aureus adhered in highest numbers to the middle and tip regions of the hyphae and adhered hardly to the head region and yeast cells. In order to give new insights into this intriguing interaction, we measured staphylococcal adhesion forces directly and found that adhesion forces experienced by $S$. aureus varied along the length of $C$. albicans hyphae and were lowest in the head region of hyphae. Importantly, staphylococcal adhesion to the hyphal head region compared well with adhesion to budding yeast cells, which means that the properties of the cell wall, with respect to bacterial adhesion, remain the same for the yeast cell and head region of hyphae upon morphological change. Interestingly, electron microscopy showed that during germination, the yeast cell wall changes its morphology at the site of hyphae initiation and further formation of the germ tube requires extensive cell wall modification $[30,31]$. The germ-tube cell wall was not only almost two times thinner than the cell wall of the parental yeast [30,31], but also much more hydrophobic (water contact angle 107 degrees) than yeast cells (water contact angle 25 degrees) [32]. Hydrophilicity of the yeast cells is caused by the presence of mannoproteinaceous, 

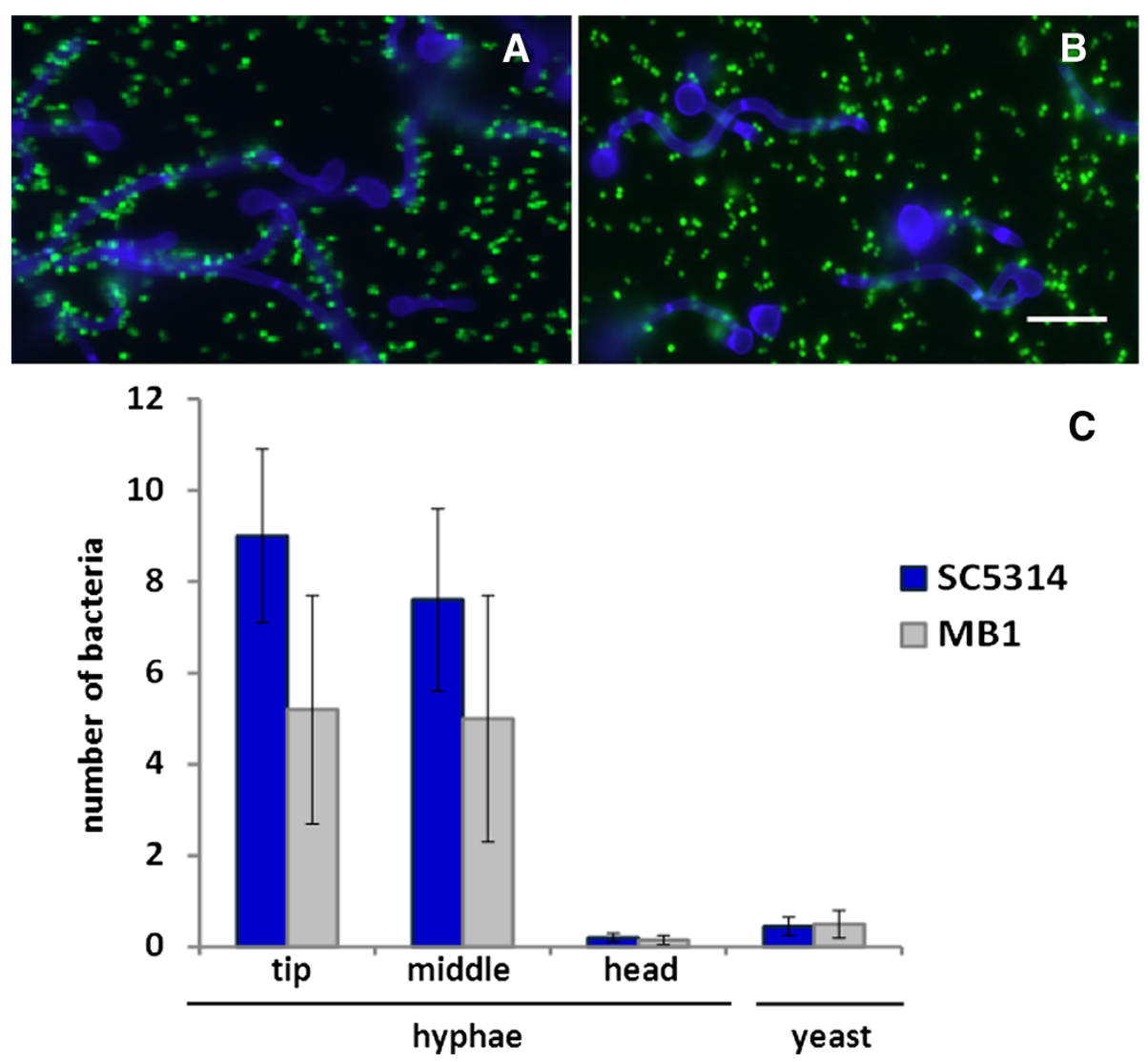

Figure 2 Microscopic analysis of inter-species interaction. Examples of fluorescent microscopic images and quantitative enumeration of the interaction between S. aureus NCTC8325-4 ${ }^{\mathrm{GFP}}$ and C. albicans strains. (A) S. aureus with C. albicans SC5314 hyphae. (B) S. aureus with C. albicans MB1 hyphae. Scale bar corresponds with $10 \mu \mathrm{m}$. (C) number of S. aureus NCTC8325-4 ${ }^{\text {GF }}$ adhering per $10 \mu \mathrm{m}$ length of different regions of $C$. albicans hyphae and yeast cells. Error bars represent SD over three experiments with separately cultured organisms and involving 30 hyphae per bacterium-fungus pair.
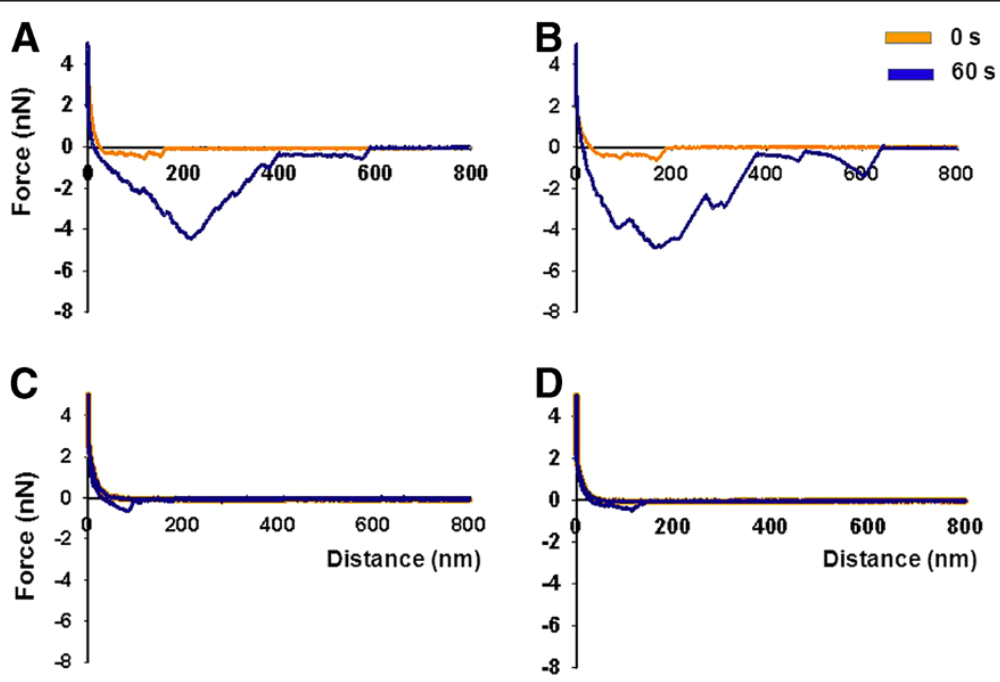

Figure 3 Representative examples of force-distance curves. Force-distance curves between different S. aureus NCTC8325-4 ${ }^{\mathrm{GFP}}$-fungus pairs upon initial contact and after 60 s bond-maturation. (A) C. albicans SC5314 hyphal tip region; (B) C. albicans SC5314 hyphal middle region; (C) C. albicans SC5314 hyphal head region; (D) C. albicans SC5314 yeast cell. 

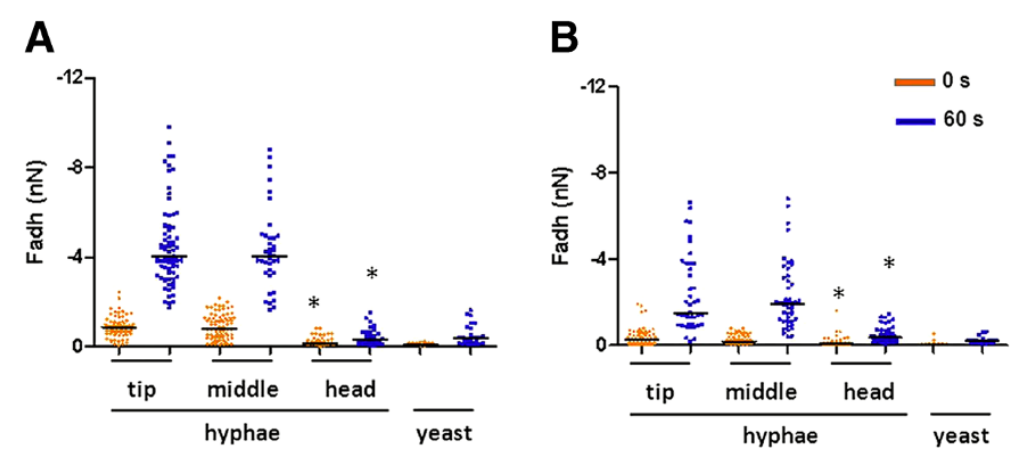

Figure 4 AFM analysis of adhesion forces between C. albicans SC5314 and S. aureus NCTC8325-4 ${ }^{\text {GFP }}$. Vertical scatter bars of adhesion forces between S. aureus NCTC8325-4 $4^{\text {GFP }}$ and different C. albicans strains and morphologies. (A) Different hyphal regions and yeast cells of C. albicans SC5314. (B) Different hyphal regions and yeast cells of C. albicans MB1. Each data point corresponds to a single force-distance curve recorded between a bacterium and a hypha. Median force values are indicated with a line. Statistically significant differences in adhesion forces ( $p<0.05$; Mann-Whitney test) of bacteria with the hyphal head region versus the middle or tip region are indicated by an asterisk.

hydrophilic, surface fibrils. Such fibrils are long, evenly spaced, radiating and mask hydrophobic proteins [33].

The biochemical composition of the cell wall of hyphae and yeast cells of $C$. albicans has been investigated extensively [34,35]. The C. albicans cell wall consists of two main layers: an outer layer of mannoproteins and an inner one that is composed of skeletal polysaccharides, such as chitin and $\beta-1,3$-glucans which confer strength and shape [34-36]. Although the basic cell wall components of $C$. albicans remain the same for hyphal and yeast cells, the amount and exposure of polysaccharides, as well as its surface proteome differ significantly [35-37]. For example, the amount of chitin in the hyphal cell wall is $3-5$ times more than in the yeast cell wall, which could be relevant for the interaction with the host's immune system [38]. Expression of a number of hypha-specific cell wall proteins, like agglutinin-like sequence 3 (Als3) protein, is up-regulated during the yeast-hyphae switch $[37,39,40]$. Als3 is specifically recognized by Streptococcus gordonii and allowed bacteria to adhere to the hyphae [41] and is also involved in adhesion of S. aureus to C. albicans hyphae [25]. Interestingly, Als3 protein was localized exclusively along complete hyphae and was not observed in the head region of hyphae nor in yeast cell walls [42]. This is in line with the current observation that there is no significant difference in adhesion forces between $S$. aureus and the relatively young tip region compared to older regions of the hypha.

Staphylococcal adhesion forces varied within the two C. albicans strains involved in this study. This effect can possibly be explained by the differential expression of cell wall associated proteins, e.g. proteins belonging to the Als family. These proteins are recognized as amyloid proteins and able to rearrange to form $\beta$-sheets, depending on environmental conditions and the strain of $C$. albicans involved [39,40,43]. Agglutinin-like sequence 3
(Als3p) is known to play a major role in the adherence process between C. albicans hyphae and S. aureus [25] and we speculate that differences in the density of Als3p along on hyphae between C. albicans SC5314 and MB1 account for the different adhesion forces measured with S. aureus. This speculation is supported by the increases in adhesion forces observed after $60 \mathrm{~s}$ surface delay, that may correspond to unzipping and rearrangement of a $\beta$ sheet-rich amyloid fibres [44].

\section{Conclusion}

The findings generated from this study quantified $S$. aureus - C. albicans interactions and demonstrated that the head region of the hyphae is different from other hyphal regions. Therewith this study combines microbiology and physical-chemistry to yield a better understanding of the fast developing field of interkingdom interactions.

\section{Competing interests}

The authors declare that they have no competing interest.

\section{Authors' contributions}

$\mathrm{ESO}, \mathrm{BPK}, \mathrm{HJB}, \mathrm{HCM}$ designed the experiment, ESO performed the experiments, ESO, BPK, HJB, HCM analyzed the data and wrote the paper. All authors read and approved the final manuscript.

\section{Acknowledgements}

This work was funded by the University Medical Center Groningen, Groningen, The Netherlands.

\section{Author details}

${ }^{1}$ Department of Biomedical Engineering, University of Groningen and University Medical Center Groningen, Antonius Deusinglaan 1, Groningen, AV 9713, The Netherlands. ${ }^{2}$ Present address: Department of Preventive Dentistry (room 12 N51), Academic Centre for Dentistry Amsterdam (ACTA), University of Amsterdam and Free University Amsterdam, Gustav Mahlerlaan 3004, Amsterdam, LA 1081, The Netherlands.

Received: 21 September 2012 Accepted: 20 November 2012 Published: 27 November 2012 


\section{References}

1. Gow NA: Growth and guidance of the fungal hypha. Microbio/ 1994, 140:3193-3205.

2. Mitchell AP: Dimorphism and virulence in Candida albicans. Curr Opin Microbiol 1998, 1:687-692.

3. Sudbery P, Gow N, Berman J: The distinct morphogenic states of Candida albicans. Trends Microbiol 2004, 12:317-324.

4. Gow NAR, Brown AJP, Odds FC: Fungal morphogenesis and host invasion. Curr Opin Microbiol 2002, 5:366-371.

5. Saville SP, Lazzell AL, Monteagudo C, Lopez-Ribot JL: Engineered control of cell morphology in vivo reveals distinct roles for yeast and filamentous forms of Candida albicans during infection. Eukaryot Cell 2003 2:1053-1060.

6. Lo HJ, Kohler JR, DiDomenico B, Loebenberg D, Cacciapuoti A, Fink GR: Nonfilamentous C. albicans mutants are avirulent. Cell 1997, 90:939-949.

7. Sudbery PE: Growth of Candida albicans hyphae. Nat Rev Microbio/ 2011, 9:737-748.

8. Lewis RE, Lo HJ, Raad II, Kontoyiannis DP: Lack of catheter infection by the efg1/efg1 cph1/cph1 double-null mutant, a Candida albicans strain that is defective in filamentous growth. Antimicrob Agents Chemother 2002, 46:1153-1155.

9. Blankenship JR, Mitchell AP: How to build a biofilm: a fungal perspective. Curr Opin Microbiol 2006, 9:588-594.

10. Nobile CJ, Mitchell AP: Genetics and genomics of Candida albicans biofilm formation. Cell Microbiol 2006, 8:1382-1391.

11. Peleg AY, Hogan DA, Mylonakis E: Medically important bacterial-fungal interactions. Nat Rev Microbiol 2010, 8:340-349.

12. Shirtliff ME, Peters BM, Jabra-Rizk MA: Cross-kingdom interactions: Candida albicans and bacteria. FEMS Microbiol Lett 2009, 299:1-8.

13. Hughes WT, Kim HK: Mycoflora in cystic fibrosis: some ecologic aspects of Pseudomonas aeruginosa and Candida albicans. Mycopathol Mycol Appl 1973, 50:261-269.

14. Pierce GE: Pseudomonas aeruginosa, Candida albicans, and device-related nosocomial infections: implications, trends, and potential approaches for control. J Ind Microbiol Biotechnol 2005, 32:309-318.

15. Falleiros RA, Norman Negri MF, Svidzinski AE, Nakamura CV, Svidzinski Tl: Adherence of Pseudomonas aeruginosa and Candida albicans to urinary catheters. Rev Iberoam Micol 2008, 25:173-175.

16. El-Azizi MA, Starks SE, Khardori N: Interactions of Candida albicans with other Candida spp. and bacteria in the biofilms. J Appl Microbio/ 2004, 96:1067-1073

17. Hogan DA, Kolter R: Pseudomonas-Candida interactions: an ecological role for virulence factors. Science 2002, 296:2229-2232.

18. Brand A, Barnes JD, Mackenzie KS, Odds FC, Gow NA: Cell wall glycans and soluble factors determine the interactions between the hyphae of Candida albicans and Pseudomonas aeruginosa. FEMS Microbiol Lett 2008, 287:48-55.

19. Diaz PI, Xie Z, Sobue T, Thompson A, Biyikoglu B, Ricker A, Ikonomou L, Dongari-Bagtzoglou A: Synergistic interaction between Candida albicans and commensal oral streptococci in a novel in vitro mucosal model. Infect Immun 2012, 80:620-632.

20. Klotz SA, Chasin BS, Powell B, Gaur NK, Lipke PN: Polymicrobial bloodstream infections involving Candida species: analysis of patients and review of the literature. Diagn Microbiol Infect Dis 2007, 59:401-406.

21. Harriott MM, Noverr MC: Candida albicans and Staphylococcus aureus form polymicrobial biofilms: effects on antimicrobial resistance. Antimicrob Agents Chemother 2009, 53:3914-3922.

22. Peters BM, Jabra-Rizk MA, Scheper MA, Leid JG, Costerton JW, Shirtliff ME: Microbial interactions and differential protein expression in Staphylococcus aureus - Candida albicans dual-species biofilms. FEMS Immunol Med Microbiol 2010, 59:493-503.

23. Carlson E: Enhancement by Candida albicans of Staphylococcus aureus, Serratia marcescens, and Streptococcus faecalis in the establishment of infection in mice. Infect Immun 1983, 39:193-197.

24. Carlson EC: Synergism of Candida albicans and delta toxin producing Staphylococcus aureus on mouse mortality and morbidity: protection by indomethacin. Zentralbl Bakteriol Mikrobiol Hyg A 1988, 269:377-386.

25. Peters BM, Ovchinnikova ES, Krom BP, Schlecht LM, Zhou H, Hoyer LL, Busscher HJ, Van der Mei HC, Jabra-Rizk MA, Shirtliff ME: Staphylococcus aureus adherence to Candida albicans hyphae is mediated by the hyphal adhesin Als3p. Microbiology 2012, doi:10.1099/mic.0.062109-0.
26. Ovchinnikova E, Krom BP, Van der Mei HC, Busscher HJ: Force microscopic and thermodynamic analysis of the adhesion between Pseudomonas aeruginosa and Candida albicans. Soft Matter 2012, 8:2454-2461.

27. Krom BP, Cohen JB, McElhaney Feser GE, Cihlar RL: Optimized candidal biofilm microtiter assay. J Microbiol Methods 2007, 68:421-423.

28. Nieto C, Espinosa M: Construction of the mobilizable plasmid pMV158GFP, a derivative of pMV158 that carries the gene encoding the green fluorescent protein. Plasmid 2003, 49:281-285.

29. Li J, Busscher HJ, Van der Mei HC, Norde W, Krom BP, Sjollema J: Analysis of the contribution of sedimentation to bacterial mass transport in a parallel plate flow chamber: part II: use of fluorescence imaging. Colloids Surf B Biointerfaces 2011, 87:427-432.

30. Cassone A, Simonetti N, Strippoli V: Ultrastructural changes in the wall during germ-tube formation from blastospores of Candida albicans. J Gen Microbiol 1973, 77:417-426.

31. Scherwitz C, Martin R, Ueberberg H: Ultrastructural investigations of the formation of Candida albicans germ tubes and septa. Sabouraudia 1978, 16:115-124.

32. Nikawa $H$, Nishimura $H$, Yamamoto T, Samaranayake LP: A novel method to study the hyphal phase of Candida albicans and to evaluate its hydrophobicity. Oral Microbiol Immunol 1995, 10:110-114.

33. Hazen KC, Hazen BW: Hydrophobic surface protein masking by the opportunistic fungal pathogen Candida albicans. Infect Immun 1992, 60:1499-1508

34. Chaffin WL, López-Ribot JL, Casanova M, Gozalbo D, Martínez JP: Cell wall and secreted proteins of Candida albicans: identification, function, and expression. Microbiol Mol Biol Rev 1998, 62:130-180.

35. Chaffin WL: Candida albicans cell wall proteins. Microbiol Mol Biol Rev 2008, 72:495-544

36. Gow NA, Van de Veerdonk FL, Brown AJ, Netea MG: Candida albicans morphogenesis and host defence: discriminating invasion from colonization. Nat Rev Microbiol 2011, 10:112-122.

37. Walker LA, Munro CA, de Bruijn I, Lenardon MD, McKinnon A, Gow NA Stimulation of chitin synthesis rescues Candida albicans from echinocandins. PLOS Pathog 2008, 4:e1000040.

38. Mora-Montes HM, Netea MG, Ferwerda G, Lenardon MD, Brown GD, Mistry AR, Kullberg BJ, O'Callaghan CA, Sheth CC, Odds FC, Brown AJ, Munro CA Gow NA: Recognition and blocking of innate immunity cells by Candida albicans chitin. Infect Immun 2011, 79:1961-1970.

39. Hoyer LL, Payne TL, Bell M, Myers AM, Scherer S: Candida albicans ALS3 and insights into the nature of the ALS gene family. Curr Genet 1998, 33:451-459.

40. Hoyer LL, Payne TL, Hecht JE: Identification of Candida albicans ALS2 and ALS4 and localization of als proteins to the fungal cell surface. J Bacteriol 1998, 180:5334-5343.

41. Silverman RJ, Nobbs AH, Vickerman MM, Barbour ME, Jenkinson HF: Interaction of Candida albicans cell wall Als3 protein with Streptococcus gordonii SspB adhesin promotes development of mixed-species communities. Infect Immun 2010, 78:4644-4652.

42. Bastidas RJ, Heitman J, Cardenas ME: The protein kinase Tor1 regulates adhesin gene expression in Candida albicans. PLoS Pathog 2009, 5:e1000294.

43. Otoo HN, Lee KG, Qiu W, Lipke PN: Candida albicans Als adhesins have conserved amyloid-forming sequences. Eukaryot Cell 2008, 7:776-782.

44. Alsteens D, Ramsook CB, Lipke PN, Dufrene YF: Unzipping a functional microbial amyloid. ACS Nano 2012, doi:10.1021/nn3025600.

doi:10.1186/1471-2180-12-281

Cite this article as: Ovchinnikova et al:: Evaluation of adhesion forces of Staphylococcus aureus along the length of Candida albicans hyphae. BMC Microbiology 2012 12:281. 